\title{
Custom Fluorescence Imaging System Exploiting Hyperspectral Camera to Characterize and Diagnose RNA Breast Cancer
}

\author{
Mohamed Aref 1,*(D), Abou-Bakr M. Youssef ${ }^{2}$, Abdallah Abdelkader Hussein ${ }^{3}$, Sara Abd El-ghaffar ${ }^{4}$, \\ Yasser H. El-Sharkawy 5 (D)
}

1 Biomedical Engineering Researcher, Egyptian Armed Forces, Cairo, EGYPT; Mh-aref@ieee.org (M.A.);

2 System \& Biomedical Engineering Department, Cairo University, Giza, Egypt, aboubakryoussef51@gmail.com (A.B.M.Y.);

3 Histopathology department, "Kobri El- Koba" Complex Hospital, Egyptian Armed Forces, Cairo, Egypt, abdallahabdelkaderhussein@gmail.com (A.A.H.);

4 Radiology Department, Maadi Armed Forces Medical Compound, Cairo, EGYPT, saraabdelghaffar_rabee3@yahoo.com (S.A.E.-g.);

5 Head of Postgraduate Studies Affairs, Military Technical College, Cairo, Egypt, yhmelsharkawy@mtc.edu.eg (Y.H.E.S.);

* Correspondence: Mh-aref@ieee.org (M.A.);

Scopus Author ID: 57217856566

Received: 5.07.2021; Revised: 2.09.2021; Accepted: 6.09.2021; Published: 19.10.2021

\begin{abstract}
Early diagnosis of breast malignancy is a challenging task to permit this cancer. RNA offers incredible potential as a biomarker for malignant growth because of its noteworthy blood dependability and characteristic articulation in various diseases. We explored the total RNA to select the optimum spectral signature concerning entire blood that could segregate between liver cancer (HCC), early breast cancer growth, and normal persons. A custom Hyperspectral Imaging (HSI) system comprises a hyperspectral camera that works in wavelength $(380 \sim 1050 \mathrm{~nm})$ with ultraviolet (UV) source light (20 $\mathrm{mW}, 395 \mathrm{~nm}$ ). It is associated with the custom software system to measure the total RNA signature of $(\mathrm{n}=50)$ subjects ( $\mathrm{n}=10 \mathrm{HCC}$ patients, $\mathrm{n}=15$ breast cancer, and $\mathrm{n}=25$ normal persons as a control). The experimental result shows that the scattering absorption of all the investigated samples is high at 395 $\mathrm{nm}$ based on (size, shape, medical state). Breast cancer RNA demonstrates fluorescence emission at $431 \mathrm{~nm}$ and $493 \mathrm{~nm}$ and Phosphorescence at $768 \mathrm{~nm}$ compared to the normal and HCC patients. Verifying the experimental results with the RNA cuvette spectral images shows that we could discriminate the HCC from the normal total RNA at $431 \mathrm{~nm}$ and the breast cancer from both normal and $\mathrm{HCC}$ at $768 \mathrm{~nm}$. This prospective investigation shows that the mutation of the total RNA regarding certain diseases affecting its spectral signature exhibits potential detection of breast tumor and HCC in tissues using extracted RNA from Blood in advance and subsequently surgery in subjects with initialstage breast cancer. A wavelength of $431 \mathrm{~nm}$ was optimum for discrimination between the HCC and the normal total RNA, and a wavelength of $768 \mathrm{~nm}$ was ideal for breast cancer discrimination.
\end{abstract}

Keywords: breast malignancy; liquid biopsy; Hyperspectral Imaging System; RNA detection; liver cancer; optical spectroscopy.

(C) 2021 by the authors. This article is an open-access article distributed under the terms and conditions of the Creative Commons Attribution (CC BY) license (https://creativecommons.org/licenses/by/4.0/).

\section{Introduction}

Breast malignancy is one of the most widely recognized cancers in women worldwide, representing around 570,000 death During the past five years [1,2]. In addition, more than 1.5 
million women are identified with malignant breast growth consistently all through the world $[3,4]$. Breast malignant is a metastatic tumor growth and can generally move to inaccessible organs like the liver, brain, bone, and lung, representing its seriousness [5].

Breast cancer early diagnostic could improve the therapeutic chance and increase the survival rates [6]. Mammography is used widely, which is considered the gold standard of breast cancer screening [7-9]. Other methods, such as Breast Magnetic Resonance Imaging (BMRI) [10,11], Breast Ultrasound (US) [12-14], Tomosynthesis Mammography (3D) [15], Automated Breast US (ABUS) [16-18], and Color Doppler [19-21].

Breast malignant generally start from the ductal hyperproliferation and afterward form into benign cancers or even metastatic carcinomas after continual incitement by different cancer-causing factors [22]. Several genes and receptors are associated with breast cancer, such as (BRCA1, BRCA2, PIK3CA, ESR1, AKT1, ERBB2, HER2, and estrogen receptors). Where mutations and abnormalities increase for together oncogenes and anti-oncogenes assume key parts in the cycles of tumor inception and movement [23-25].

DNA (Deoxyribonucleic acid) and RNA (Ribonucleic-acid) supply and relocate genetic information in living organisms, where DNA: the main component of the nucleus/secure demonstration of complete genetic makeup organism, RNA: exist in the cytoplasm and nucleus/key to data stream inside a cell [26,27].

DNA sequencing has been a backbone of life science innovative work. Although 1990 was the beginning of the launch of the human genome project, next in 1995 was the first bacterium sequencing (influenza). Later, the cancer genome atlas in 2012 published exome sequences from 507 breast cancer [28]. During the previous few years, scientific studies have exhibited the capacity to dependably recognize and evaluate circulating cell-free malignant growth DNA and RNA, for the most part in patients with metastatic sickness [29,30].

DNA and RNA quantification is commonly signified to the same extent as nucleic acid quantification to conclude the mean concentration of the DNA or RNA. Additionally, Sample purity is a significant thought to precisely figure the measure in a sample of DNA or RNA [31,32]. There are two common methods to quantify the DNA or RNA [33].

\subsection{The Photometry Ultraviolet-Visible measurement (UV-Vis).}

This method is based on a measurement of nucleic acids (DNA and RNA) absorption. The measured light reached the detector afterward passing through the investigated sample is measured concerning incident light. However, the standard UV-Vis absorption spectrum displays a high peak at $260 \mathrm{~nm}$. The schematic Diagram of the Photometry (UV-Vis) and the ideal absorption spectrum are more illustrated in Figure A1 in the appendix. Although, one of the features of this system (simple, no sample preparation with dyes or standards, and could measure purity ratios directly). On the other hand, the disadvantages of this method (cannot differentiate between DNA or RNA, and provide limited sensitivity).

\subsection{The Fluorescence measurement.}

The fluorometric method for nucleic acids relies on fluorogenic dyes, which combine precisely with DNA or RNA. The signal is calculated by fluorometers by sample excitation with a precise wavelength. Where the schematic Diagram of the fluorescence RNA/DNA quantification demonstrating the optical measurement theory with typically measured Fluorescence signal is displayed in Figure A2 in the appendix. However, the advantages of this 
system (precise measurement "DNA, ds DNA, ssDNA, and RNA", sensitive as it could measure $\mathrm{pg} / \mathrm{mL}$, accurate despite nucleic acid contaminants). Conversely, the disadvantages of this method (It consumes a lot of time during the test for reagent and sample preparation and it does not provide the purity`s information).

Cellular "total" RNA: contains messenger RNA (mRNA) representing (1 5\%) which functions as a template for protein synthesis, Ribosomal RNA (rRNA) representing ( $\geq 80 \%$ ) provides the structural component of ribosomes, Transfer RNA (tRNA) representing (10 15 $\%)$ which translates mRNA data into the proper amino acid, where total RNA could be extracted from biological samples by either "Organic extraction" or "Affinity purification" to isolating RNA from the other cellular components [34,35].

The fluorescence process is a result of an interaction that happens when certain atoms called fluorophores or fluorescent dyes absorb light. The assimilation of light by a populace of these particles raises their energy level to a concise, energized state. The theory is more explained in the "Jablonski diagram", as displayed in Figure A3 in the appendix [36]. The Jablonski diagram introduces the light absorption, the vibrational relaxation energy as "Fluorescence", the intersystem crossing process as "Phosphorescence", and the spontaneous low-intensity transition as "Delayed Fluorescence" [37,38].

Hyperspectral imaging (HSI) is a fast progressing and non-invasive imaging method with vast capability for clinical applications. HSI had been exploited in head and neck tumor detection [39]. In the ex-vivo breast malignant detection [40-42]. In Prostate tumor detection [43]. Monitoring of the Liver thermal ablation [44-46]. Furthermore, exploiting the HSI in observing radiofrequency ablation [47] and laser ablation therapy exploited for minimum invasive liver tumor exclusion [48]. Additionally, in the measurement of oxygen saturation in the blood and spectral blood vessel delineation [49,50].

In the proposed investigation, we measured the spectral signature of the total RNA mutation in plasma of liver cancer (HCC) and breast cancer patients and in healthy persons as controls, where all measurements are label-free (without anybody injection). We also examined the Fluorescence and side scattering signatures for these cases. Furthermore, we could segregate between the total RNA of the breast cancer concerning the healthy and the HCC investigated samples exploiting HSI capabilities to measure the breast cancer Fluorescence signature.

\section{Materials and Methods}

\subsection{The presented approach interconnections processes.}

Sample preparation from the liquid biopsy (blood).

$>$ Hyperspectral (HS) scan Images of the investigated samples.

The measurements of sample Fluorescence and side scattering signature.

Applying the Custom algorithm.

\subsection{The breast cancer detection exploiting optical imaging system.}

The system incorporated a hyperspectral (HS) camera, UV light source, and image processing algorithm (normalization, moving average filter to remove the unwanted noise) were exploited as channels to detect the breast cancer fluorescence signature from a liquid biopsy. To attain the necessary HSI records, we utilized the HS camera (Surface Optics, SOC710, USA) with $5 \mathrm{~nm}$ spectral resolution, 128 spectral channels, and a push broom. The 
camera is integrated with a lens (Schneider, 1.9/35, Range 400 1000 nm, Germany). The utilized source light assembly for the HS image scan (THORLABS UV source, $50 \mathrm{~mW}$, USA) with wavelength $(395 \mathrm{~nm})$.

The capturing time for each image is about $5 \sim 12 \mathrm{sec}$ and calculation time is 10-15 sec using DADiSP/SE software (DSP Development Corporation,6.7 student edition, 2020, USA) on a personal laptop (DELL, Intel-core i7,1.8GHz,16 GB RAM, USA), the system Schematic Diagram illustrated in Figure 1.

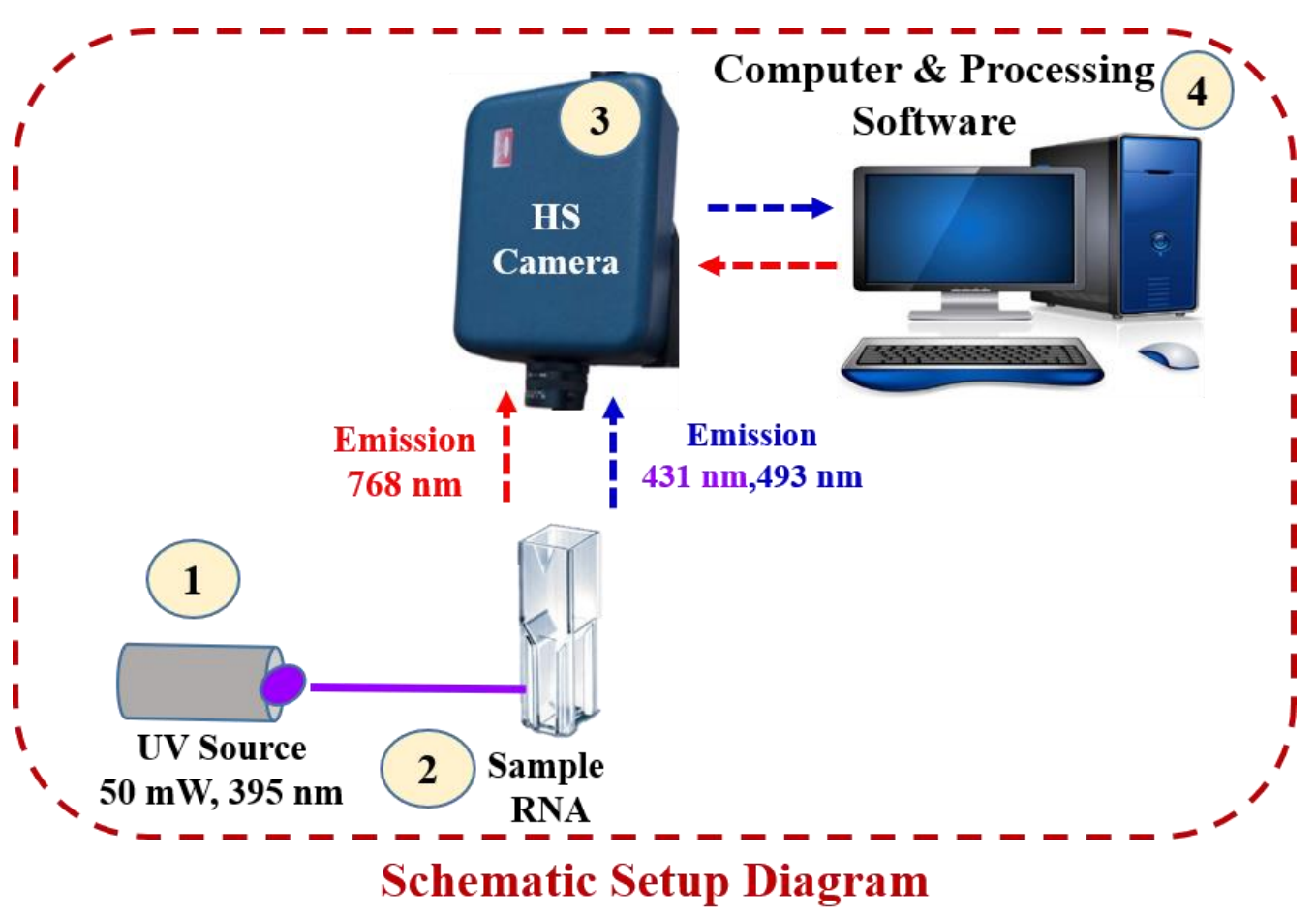

Figure 1. The Schematic Diagram for the investigated System, (1) The Incorporating UV light source (50 $\mathrm{mW}, 395 \mathrm{~nm}$ ), (2) The Investigated Sample for the total RNA, (3) The exploited Hyperspectral camera (Surface Optics, SOC710, USA), (4) The Computer and the Image Processing Algorithm.

\subsection{Design of the study.}

The experimental study design was conducted during the period from October 2019 to February 2020 at "Kobri El Koba Military Complex Hospital". The study was ethically approved by the Institutional Ethical Committee of the "Faculty of Medicine, Ain Shams University, Egypt (No: P.T.REC/009/003156)" and followed the Declaration of Helsinki Ethical Principles for Medicinal Research Comprising Human Subjects. All patients read and signed two copies of a consent form before the beginning of data collection.

\subsection{Subject and sample preparation.}

We extracted the total RNA from fresh human blood of ( $\mathrm{n}=50)$ subjects who agreed to participate in the experiment $(n=10 \mathrm{HCC}$ patients, $n=15$ breast cancer, and $n=25$ normal persons as a control). We exploited Mini Kit (Geneoid, RB050/100/300, Taiwan) [51]. We utilized the whole Blood sample Volume $(300 \mu \mathrm{l})$ for each participated subject. Exploiting RBC Lysis Buffer (Cleansers and chaotropic salt) from the identified kit to lyse cells and deactivate RNase, the RNA was attached by the glass fiber matrix (membrane optimized for total RNA extraction), while contaminants remain suspended. Next, remove the contaminants with wash buffer while the RNA remains bound to the membrane. Finally, the total RNA is 
eluted by RNase-free water and ready for the experimental investigation measurements. The sample preparation is more clarified in Figure 2.

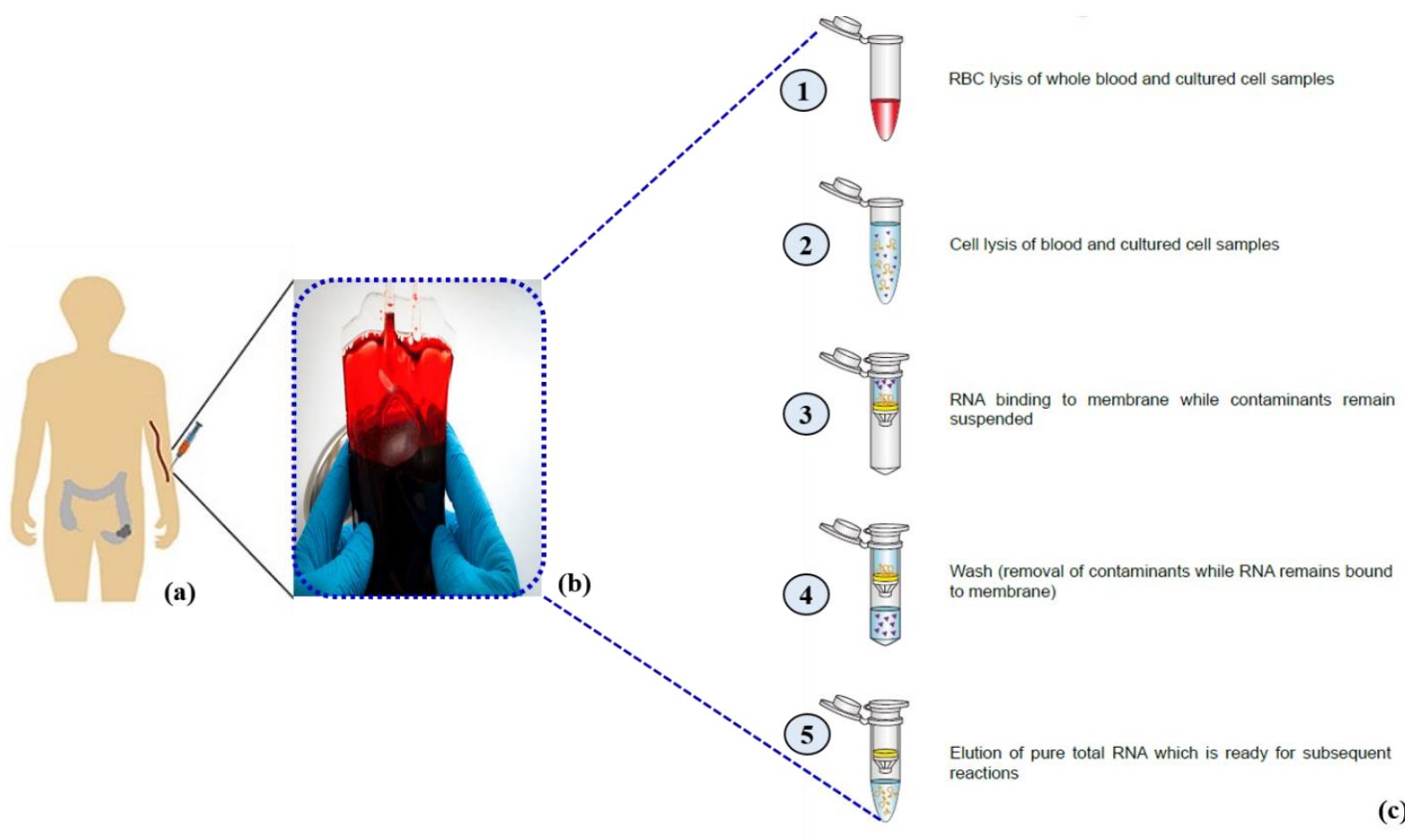

Figure 2. The sample Preparation to Extract the Total RNA; (a) Blood Sample withdrawal from the Participated Investigated Subjects; (b) The Fresh Blood Bag of the Investigated Subjects; (c) The Total RNA Extraction Process, (1) The whole Blood sample Volume $(300 \mu \mathrm{l})$, (2) Cleansers and chaotropic salt are exploited to lyse cells and deactivate RNase, (3) The RNA is attached by the glass fiber matrix while contaminants remain suspended, (4) Removing of the contaminants with wash buffer while the RNA remains bound to the membrane,

(5) The total RNA is eluted by RNase-free Water and ready for the experimental investigations.

\subsection{Custom Image Algorithm.}

An essential enhancement in HSI and in-advance of image acquisition is a level field correction for data normalization. A highly reflected board (white) and a low reflected board (dark) were exploited to attain relative reflectance from the inspected sample [52]. The dark cube was detained by closing the HS camera cap. Data from a dark image and white equilibrium assessments were used to address the intentional material picture. The important objective of this alteration is to remove impacts on the inspected tissue, as presented in equation (1):

$$
\mathrm{RF}(\vartheta)=\frac{\operatorname{Ip}(\vartheta)-\mathrm{I} \beta(\vartheta)}{\operatorname{Iw}(\vartheta)-\mathrm{I} \beta(\vartheta)} \times 100 \%
$$

where $\operatorname{RF}(\vartheta)$ is the reflectance of the inspected sample image, $\operatorname{Ip}(\vartheta)$ is the caught picture, $\mathrm{I} \beta(\vartheta)$ is the dark captured image with a closing lens, and $\operatorname{Iw}(\vartheta)$ is the acquired whiteboard picture.

Occupying Data-normalization on the acquired image to remove the unnecessary interference. The initially captured images vary because of the incident light and temperature divergences; spectral images must be normalized involving pixel normalization, as illustrated in equation (2).

$$
I_{\text {new }}=\left(I_{\text {previous }}-\min _{\text {previous }}\right) \frac{\text { max }_{\text {new }}-\text { min }_{\text {new }}}{\text { max }_{\text {previous }}-\text { max }_{\text {previous }}}+\min _{\text {new }}
$$

Although, normalization modifies an m-dimensional grayscale successive image $I_{\text {previous }}:\{A\}$ with intensity estimations in the range ( $\left.\min _{\text {previous }}\right)$ to the extreme 
( $\max _{\text {previous }}$ ) into a different image $I_{n e w}:\{A\}$ with intensity ratios at the minimum range $\left(\min _{n e w}\right)$ to the extreme $\left(\max _{n e w}\right)$.Then, employing the Moving average filter as a filter at kernel value $=10$ for noise eradication and image enhancement [53], as clarified in equation (3).

$$
f(x \times y)=\frac{1}{q t}+\sum_{(r \times c) \in W}^{\infty} S(\mathrm{r} \times \mathrm{c})
$$

Where ' $S$ ' is the noisy picture, $f(\mathrm{x} \times \mathrm{y})$ is the restored picture, and ' $\mathrm{r}$ ' and ' $c$ ' for the row and column coordinates correspondingly, within a window ' $\mathrm{W}$ ' of size ' $q \times t$ ' where the procedure takes place.

In the presented prospective study, we investigated the total RNA of $(n=50)$ participating subjects ( $n=10$ HCC patients, $n=15$ breast cancer, and $n=25$ normal persons as a control), where the hyperspectral camera works in a wavelength $(380 \sim 1050 \mathrm{~nm})$ with ultraviolet (UV) as source light at a wavelength $(395 \mathrm{~nm})$. We measured the diffuse reflectance and the fluorescence signature of all the samples to select the optimum spectral signature which could segregate between liver cancer (HCC), early breast cancer growth, and normal persons.

\section{Results and Discussion}

Concerning the system interconnections techniques and processes, they are preliminary from hyperspectral image scanning for the inspected samples and applying the custom image processing to measure the spectral signatures (diffuse reflectance / Fluorescence / Phosphorescence) of the investigated samples (Normal subject / HCC Patient / Breast Cancer Patient).

Although, we noticed from the measured 1-D spectral signature that the investigated samples (Normal subject / HCC Patient / Breast Cancer Patient) are high absorption at the wavelength $(395 \mathrm{~nm})$ based on (size, shape, previous medical history, recent medical state) for each case concerning the ultraviolet (UV) source light $(20 \mathrm{~mW}, 395 \mathrm{~nm})$. However, the Total RNA Spectral Signature of the Breast Cancer (in the green dotted line) Demonstrates Emission at $431 \mathrm{~nm}$ and $493 \mathrm{~nm}$ and Phosphorescence at $768 \mathrm{~nm}$ concerning the Normal (solid blue line) and HCC patients (Red dotted line), as shown in Figure 3.

We used the measured 1-D spectral signature to select the optimum spectral images to apply the custom image processing and verify the experimental results with the RNA cuvette spectral images. Consequently, we apply the custom image processing on the acquired scanned cube images for each type of investigated sample separately to validate the hypothesis regarding the spectral signatures.

Initially, we examined the normal control total RNA samples and we used the measured 1-D spectral signature as guidance to select the optimum spectral images at the selected wavelengths $(395 \mathrm{~nm}, 431 \mathrm{~nm}, 493 \mathrm{~nm}$, and $768 \mathrm{~nm})$. Where the complete worksheet for the scanned normal control total RNA samples demonstrating the spectral images at each wavelength, then the applied custom image processing is displayed in Figure A4 in the appendix.

Even though the scanned Cube image for the normal control total RNA samples shows high absorption at a wavelength $(395 \mathrm{~nm})$ regarding the excitation source light (UV, $20 \mathrm{~mW}$, $395 \mathrm{~nm}$ ), as shown in Figure 4-a, on the other hand, the sample did not glow or represent any emissions at a wavelength (431 nm), as displayed in Figure 4-b. Subsequently, the sample provides high emission at a wavelength $(493 \mathrm{~nm})$ and almost vanished with no emission at a wavelength (768 nm), as demonstrated in Figure 4-c and Figure 4-d, respectively. 


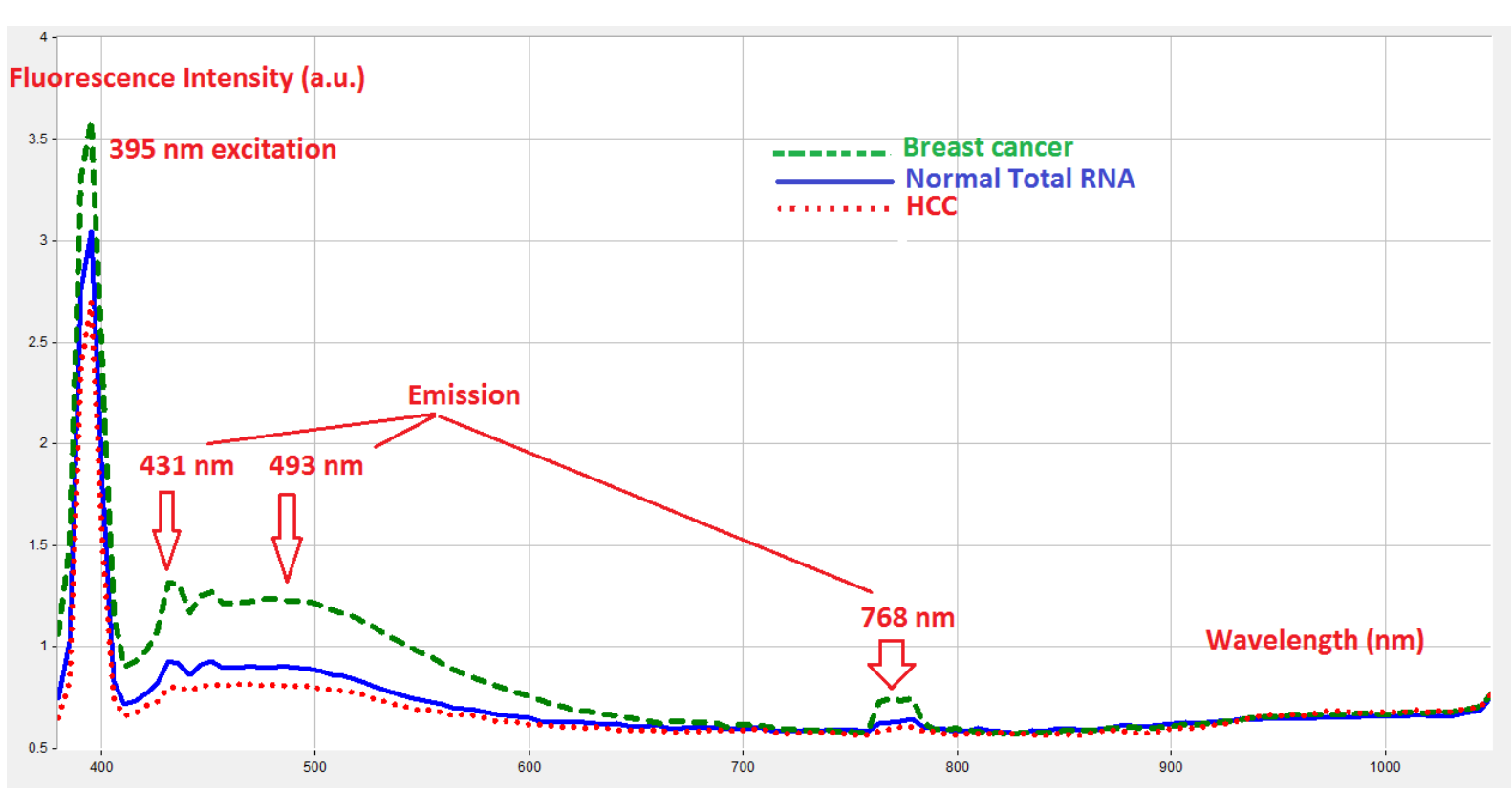

Figure 3. The Spectral Signature of Three of the Investigated Samples (Normal subject / HCC Patient / Breast Cancer Patient) Identifying the High Absorption of the whole Samples at a wavelength (395 $\mathrm{nm}$ ) regarding the Ultraviolet (UV) source light (20 mW, $395 \mathrm{~nm})$, where the Total RNA Spectral Signature of the Breast Cancer (dotted green line) Demonstrates Emission at $431 \mathrm{~nm}$ and $493 \mathrm{~nm}$ and Phosphorescence at $768 \mathrm{~nm}$ with respect to the Normal (solid blue line) and HCC patients (Red dotted line).

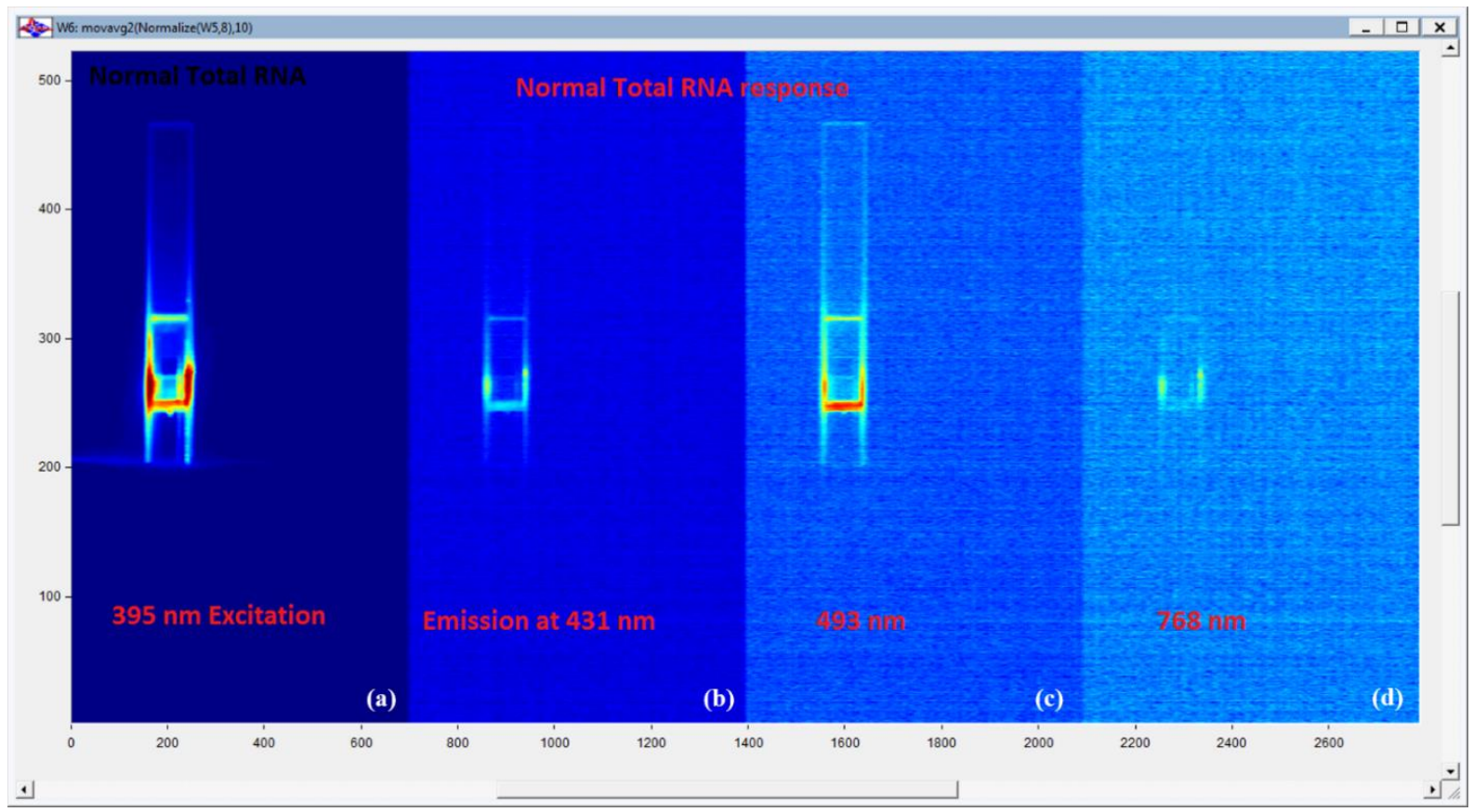

Figure 4. The worksheet window of the scanned Cube image for the normal control total RNA samples exploiting the proposed hypothesis for the spectral signature images after applying the custom image processing; (a) The sample was highly absorption at a wavelength $(395 \mathrm{~nm})$ regarding the excitation source light (UV, $20 \mathrm{~mW}, 395 \mathrm{~nm}$ ), (b) The sample did not glow or represent any emissions at a wavelength $(431 \mathrm{~nm}),(\mathbf{c})$ The sample provides high emission at a wavelength $(493 \mathrm{~nm}),($ d) The sample is almost disappeared with no emission at a wavelength $(768 \mathrm{~nm})$.

Next, we investigated the HCC samples and applied the same previous procedures done with the normal control total RNA samples by selecting the spectral images at the wavelengths (395 nm, $431 \mathrm{~nm}, 493 \mathrm{~nm}$, and $768 \mathrm{~nm}$ ) with respect to the measured 1-D spectral signature. The complete worksheet for the scanned HCC total RNA samples demonstrated the spectral 
images at each wavelength, and the applied custom image processing is displayed in Figure A5 in the appendix.

Despite the fact, the scanned Cube image for the HCC total RNA samples shows high absorption at a wavelength $(395 \mathrm{~nm})$ regarding the excitation source light (UV, $20 \mathrm{~mW}, 395$ $\mathrm{nm}$ ), as shown in Figure 5-a. On the other hand, the sample represents a little bit of emission at a wavelength $(431 \mathrm{~nm})$, as displayed in Figure 5-b. Subsequently, the sample provides high emission at a wavelength $(493 \mathrm{~nm})$ and almost vanished with no emission at a wavelength (768 $\mathrm{nm}$ ), as demonstrated in Figure 5-c and Figure 5-d, respectively.

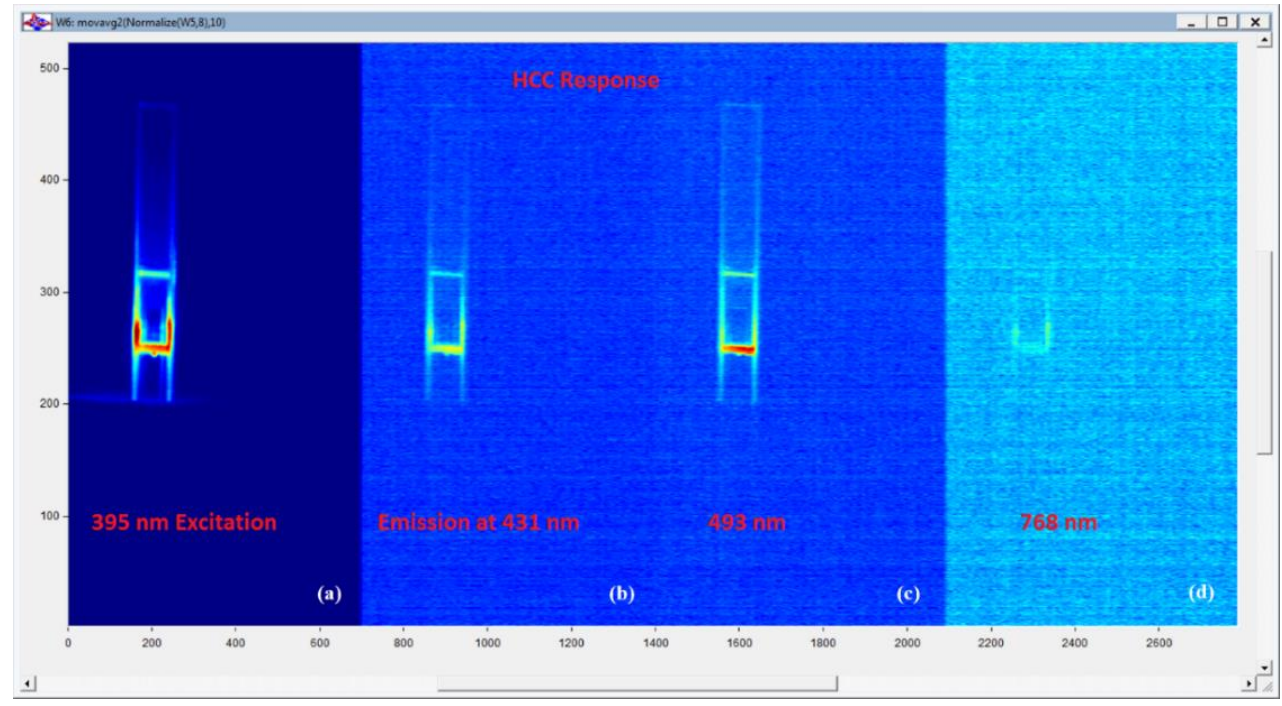

Figure 5. The worksheet window of the scanned Cube image for the HCC total RNA samples exploiting the proposed hypothesis for the spectral signature images after applying the custom image processing; (a) The sample was highly absorption at a wavelength $(395 \mathrm{~nm})$ regarding the excitation source light (UV, $20 \mathrm{~mW}, 395$ $\mathrm{nm})$, (b) The sample represents a little bit emission at a wavelength $(431 \mathrm{~nm}),(\mathbf{c})$ The sample provides high emission at a wavelength $(493 \mathrm{~nm}),(\mathbf{d})$ The sample is almost disappeared with no emission at a wavelength

(768 nm).

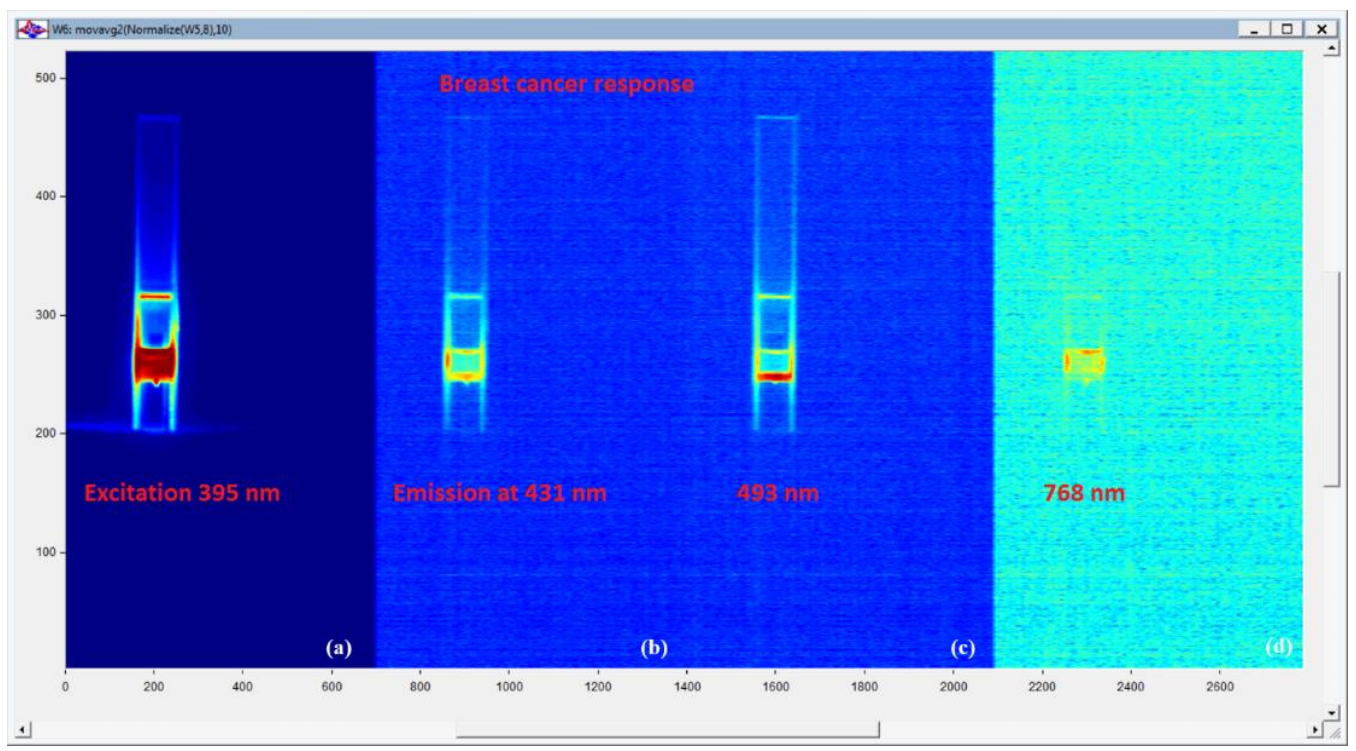

Figure 6. The worksheet window of the scanned Cube image for the Breast Cancer total RNA samples exploiting the proposed hypothesis for the spectral signature images after applying the custom image processing; (a) The sample was highly absorption at a wavelength $(395 \mathrm{~nm})$ regarding the excitation source light

(UV, $20 \mathrm{~mW}, 395 \mathrm{~nm}$ ), (b) The sample represents a moderate emission at a wavelength (431 nm), (c) The sample provides high emission at a wavelength $(493 \mathrm{~nm}),(\mathbf{d})$ The sample still representing emission at a wavelength $(768 \mathrm{~nm})$. 
Furthermore, investigating the breast cancer samples at the selected wavelengths (395 $\mathrm{nm}, 431 \mathrm{~nm}, 493 \mathrm{~nm}$, and $768 \mathrm{~nm}$ ) concerning the measured 1-D spectral signature. Despite the fact, the scanned Cube image for the breast cancer total RNA samples shows high absorption at a wavelength $(395 \mathrm{~nm})$ regarding the excitation source light (UV, $20 \mathrm{~mW}, 395$ $\mathrm{nm}$ ), as shown in Figure 5-a. On the other hand, the sample represents a moderate emission at a wavelength $(431 \mathrm{~nm})$, as displayed in Figure 5-b. Subsequently, the sample provides high emission at a wavelength $(493 \mathrm{~nm})$ and still represents emission at a wavelength $(768 \mathrm{~nm})$, as demonstrated in Figure 5-c and Figure 5-d, respectively.
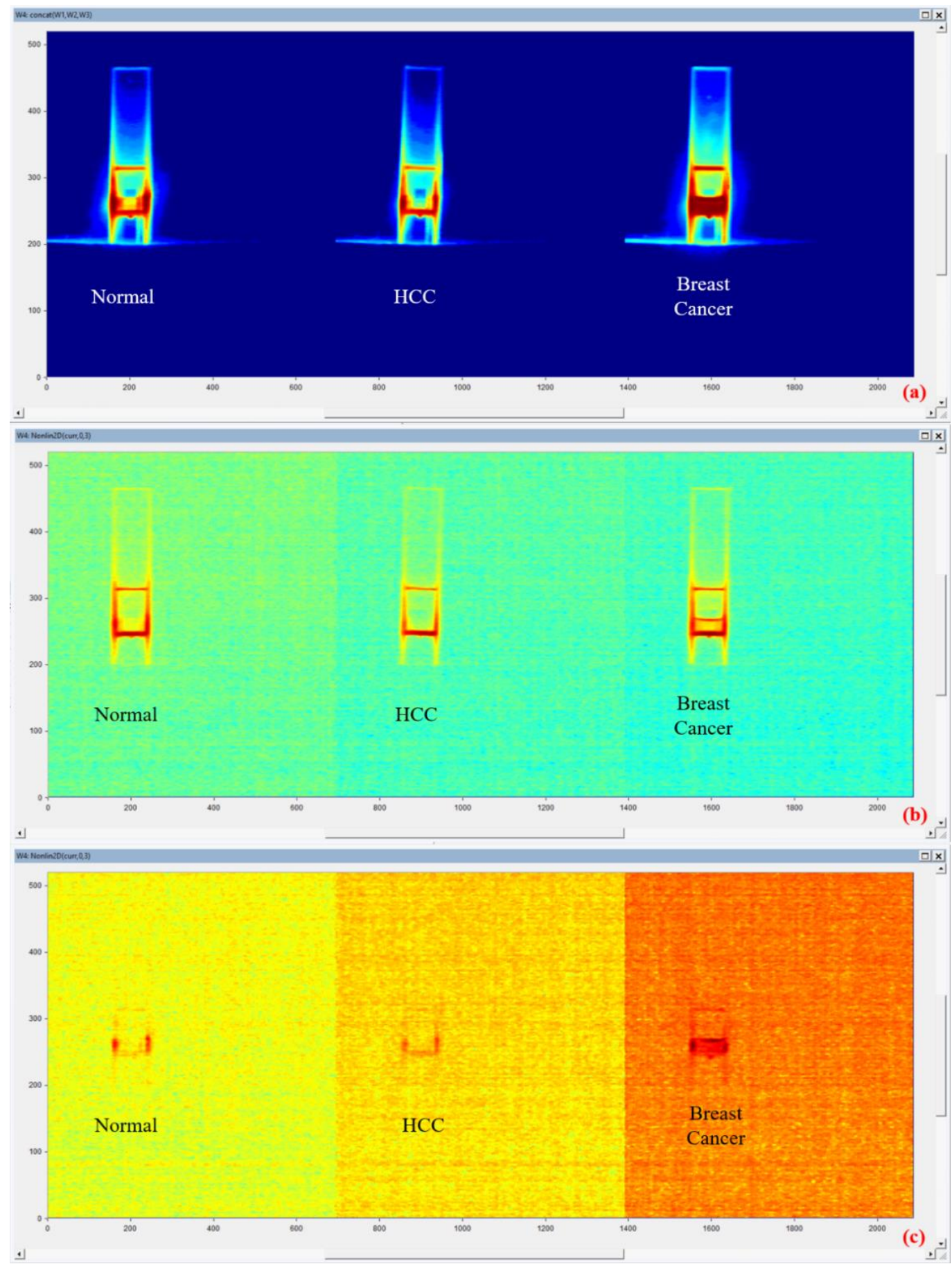

Figure 7. (a) The three investigated samples (Normal subject / HCC Patient / Breast Cancer Patient) at wavelength (395 nm), (b) The three investigated samples (Normal subject / HCC Patient / Breast Cancer Patient) at wavelength $(431 \mathrm{~nm})$, (c) The three investigated samples (Normal subject / HCC Patient / Breast Cancer Patient) at wavelength $(768 \mathrm{~nm})$. 
Finally, for the result validation, we repeat the experiment of the investigated samples (Normal subject / HCC Patient / Breast Cancer Patient) at the same time concerning the three different wavelengths $(395 \mathrm{~nm}, 431 \mathrm{~nm}, 768 \mathrm{~nm})$. At each wavelength $(395 \mathrm{~nm}, 431 \mathrm{~nm}, 768$ $\mathrm{nm}$ ), we measure each case's emission intensity, as clarified in the entire worksheet in Figure A6, Figure A7, Figure A8 in the appendix, respectively. Figure 7 was constructed from Figure A6-d, Figure A7-d, Figure A8-d in the appendix to highlight the emission variation for each case at the various wavelengths (395 nm, $431 \mathrm{~nm}, 768 \mathrm{~nm})$.

Breast tumor is the most widespread tumor among women worldwide [54]. The occurrence of breast tumors is recognized to the escalation with age [55,56], essentially due to the mammary glands of bodily mutations [57]. Liable on the various subtypes, early-stage breast tumor is responsive to therapeutic cancer resection surgery. In spite of this, early-stage breast tumor detection is a challenging task. Furthermore, it is vital for decreasing cancerrelated mortality [58]. However, its consequence varies with respect to the types and grades of the disease. For breast tumor grade II and III, the tumor development is much faster than grade I. Therefore, the survival and diagnosis could be significantly enhanced with an early diagnostic for the tumor $\leq 2 \mathrm{~cm}[59]$.

Breast tumor is frequently divided into several subtypes regarding the tumor's molecular landscape $[60,61]$. Conventional methods for breast cancer diagnosis, for instance, tissue biopsy, are not inclusive enough to acquire the whole genomic landscape of breast cancers. But, with the institution of novel methods, the relevance of liquid biopsy has been improved with respect to breast cancer management incorporating (cancer early detection, monitoring, the expectation of diagnosis, and response to therapy) [62].

Throughout the formation and development of the initial malignant tumor, numerous components are discharged into the blood resulting in apoptosis and necrosis $[63,64]$. Some of which incorporate cell-free RNA ( RNA $_{\text {cf }}$ ), circulating tumor cells (CTCs), and circulating tumor DNA ( $\left.\mathrm{DNA}_{\mathrm{ct}}\right)$. Applications of liquid biopsy have the ability to address the necessity for a customized non-invasive tumor screening system. Consequently, various components of breast cancers in the blood can be employed for more successful diagnosis, expectation prognosis, targeted therapeutic, and detection of resistance development [65].

The proposed system incorporates (side scattering, fluorescence, Phosphorescence) measurements. Where fluorescence phenomena were investigated thru the measurement of the spectral signatures of the investigated samples (Normal subject / HCC Patient / Breast Cancer Patient) with respect to the changes of the optical properties for each sample, this was achieved by exploiting the HSI system with source light UV light (UV, $20 \mathrm{~mW}, 395 \mathrm{~nm}$ ).

We observed from the measured 1-D spectral signature of the investigated total RNA samples are highly absorbed in a wavelength $(395 \mathrm{~nm})$ with respect to the UV source light (20 $\mathrm{mW}, 395 \mathrm{~nm}$ ). The normal cases were displayed in (solid blue line) and HCC patients (Red dotted line), and the Breast Cancer (in the green dotted line). However, the total RNA spectral signature of the breast cancer demonstrates emission at $431 \mathrm{~nm}$ and $493 \mathrm{~nm}$ and Phosphorescence at $768 \mathrm{~nm}$ with respect to the Normal (solid blue line) and HCC patients (Red dotted line), as shown in Figure 3.

We used the measured 1-D spectral signature as guidance to select the optimum spectral images to validate the output result. The scanned cube images for each type of the investigated sample were processed to remove the unnecessary background noise and enhance the images at the selective wavelengths ( $395 \mathrm{~nm}, 431 \mathrm{~nm}, 493 \mathrm{~nm}$, and $768 \mathrm{~nm}$ ). 
We initially examined the normal control total RNA samples spectral images at the selected wavelengths ( $395 \mathrm{~nm}, 431 \mathrm{~nm}, 493 \mathrm{~nm}$, and $768 \mathrm{~nm}$ ). However, we noticed that for the normal control, total RNA samples show high absorption at a wavelength $(395 \mathrm{~nm})$ with respect to the excitation source light (UV, $20 \mathrm{~mW}, 395 \mathrm{~nm}$ ), as shown in Figure 4-a. However, the sample did not glow or represent any emissions at the wavelength $(431 \mathrm{~nm})$, as displayed in Figure 4-b. Subsequently, the sample provides high emission at the wavelength (493 nm) and almost vanished with no emission at the wavelength $(768 \mathrm{~nm})$, as demonstrated in Figure 4-c and Figure 4-d, respectively. Furthermore, the complete worksheet for the normal total RNA samples is more clarified in Figure A4 in the appendix.

Then, we investigate the HCC total RNA samples at the selected wavelengths (395 nm, $431 \mathrm{~nm}, 493 \mathrm{~nm}$, and $768 \mathrm{~nm}$ ) with respect to the measured 1-D spectral signature. Despite the fact, the HCC total RNA samples show high absorption at a wavelength (395 nm), as shown in Figure 5-a. On the other hand, the sample represents a little bit of emission at the wavelength (431 nm), as displayed in Figure 5-b. Subsequently, the sample provides high emission at the wavelength $(493 \mathrm{~nm})$ and almost vanished with no emission at the wavelength $(768 \mathrm{~nm})$, as demonstrated in Figure 5-c and Figure 5-d, respectively. Additionally, the complete worksheet for the HCC total RNA samples is more elucidated in Figure A5 in the appendix.

Furthermore, the breast cancer total RNA samples were investigated at the selected wavelengths ( $395 \mathrm{~nm}, 431 \mathrm{~nm}, 493 \mathrm{~nm}$, and $768 \mathrm{~nm}$ ). The scanned Cube image for the breast cancer total RNA samples shows high absorption $(395 \mathrm{~nm})$ wavelength, as shown in Figure 6a. The sample represents a moderate emission at the wavelength $(431 \mathrm{~nm})$, as displayed in Figure 6-b. Consequently, the sample provides high emission at the wavelength $(493 \mathrm{~nm})$ and still represents emission at the wavelength $(768 \mathrm{~nm})$, as demonstrated in Figure 6-c and Figure 6-d, respectively.

Finally, for data validation, we explored the investigated samples (Normal subject / HCC Patient / Breast Cancer Patient) instantly with respect to the three different wavelengths (395 nm, $431 \mathrm{~nm}, 768 \mathrm{~nm}$ ) to highlight the emission variations for each case.

However, Figure A6 in the appendix presents the three investigated samples (Normal subject / HCC Patient / Breast Cancer Patient) at wavelength $395 \mathrm{~nm}$. From Figure A6-e, we calculate the emission intensity for each case at the scanned line $269 \mathrm{Y}$-axis with values (Normal $=175$ A.U, HCC $=90$ A.U, Breast cancer $=250$ A.U). Then, from Figure A7 in the appendix, we calculate the emission intensity for each case at wavelength $431 \mathrm{~nm}$ for the scanned line 269 Y-axis with values (Normal $=165$ A.U, HCC $=140$ A.U, Breast cancer $=185$ A.U). Furthermore, from Figure A8 in the appendix, we calculate the emission intensity for each case at wavelength $768 \mathrm{~nm}$ for the scanned line $269 \mathrm{Y}$-axis with values (Normal $=155$ A.U, HCC $=150$ A.U, Breast cancer $=210$ A.U). Finally, Figure 7 was constructed from Figure A6-d, Figure A7-d, Figure A8-d in the appendix to highlight the emission variation for each case at the various wavelengths $(395 \mathrm{~nm}, 431 \mathrm{~nm}, 768 \mathrm{~nm})$.

\section{Conclusions}

A customized optical imaging system incorporating the HS camera has been launched to distinguish between breast cancer and HCC using a particular spectral signature for total RNA with a promising result associated with a respectable accuracy and sensitivity in minimum investigation time. The experimental result shows that all the investigated samples (normal / HCC/ breast cancer) have high absorption at wavelength $395 \mathrm{~nm}$. Breast cancer RNA demonstrates emission at $431 \mathrm{~nm}, 493 \mathrm{~nm}$, and Phosphorescence at $768 \mathrm{~nm}$ compared to the 
normal and HCC patients. Verifying the experimental results with the RNA cuvette spectral images shows that we could discriminate the HCC from the normal total RNA at $493 \mathrm{~nm}$ and the breast cancer from both normal and $\mathrm{HCC}$ at $768 \mathrm{~nm}$. In future work, we intend to build a simple and low-cost system to work with a commercially charge-coupled device (CCD) camera to be exploited in cancer (breast cancer / HCC) early detection and infectious syndromes.

\section{Funding}

The authors state and declare that this research did not receive any external funding.

\section{Conflicts of interest}

The authors state and declare that there are no conflicts or competing interests. All the coauthors agreed to the publication of this research study

\section{Ethics approval}

The experimental study design was conducted from October 2019 to February 2020 at "Kobri El Koba Military Complex Hospital". The study was ethically approved by the Institutional Ethical Committee of the "Faculty of Medicine, Ain Shams University, Egypt (No: P.T.REC/009/003156)" and followed the Declaration of Helsinki Ethical Principles for Medicinal Research Comprising Human Subjects.

\section{Consent to participate}

All patients read and signed two copies of a consent form before data collection and within this research study.

\section{Availability of data and material}

The authors state and declare that all data exist and are available.

\section{Code availability}

The authors state and declare that all code exists and is available.

\section{References}

1. Dibden, A.; Offman, J.; Duffy, S.W.; Gabe, R. Worldwide review and meta-analysis of cohort studies measuring the effect of mammography screening programmes on incidence-based breast cancer mortality. Cancers (Basel) 2020, 12, https://doi.org/10.3390/cancers12040976.

2. Sung, H.; Ferlay, J.; Siegel, R.L.; Laversanne, M.; Soerjomataram, I.; Jemal, A.; Bray, F. Global Cancer Statistics 2020: GLOBOCAN Estimates of Incidence and Mortality Worldwide for 36 Cancers in 185 Countries. CA. Cancer J. Clin. 2021, 71, 209-249, https://doi.org/10.3322/caac.21660.

3. Sopik, V. International variation in breast cancer incidence and mortality in young women. Breast Cancer Res. Treat. 2021, 186, 497-507, doi:10.1007/s10549-020-06003-8.

4. Ferlay, J.; Colombet, M.; Soerjomataram, I.; Parkin, D.M.; Piñeros, M.; Znaor, A.; Bray, F. Cancer statistics for the year 2020: An overview. Int. J. Cancer 2021, 149, 778-789, https://doi.org/10.1002/ijc.33588.

5. Sun, Y.; Zhao, Z.; Yang, Z.; Xu, F.; Lu, H.; Zhu, Z.; Shi, W. Risk Factors and Preventions of Breast Cancer 2017, 13, https://doi.org/10.7150/ijbs.21635.

6. DeSantis, C.E.; Jemal, A. Re: Black-White breast cancer incidence trends: effects of ethnicity. JNCI J. Natl. Cancer Inst. 2019, 111, 99-100.

7. Gøtzsche, P.C.; Jørgensen, K.J. Screening for breast cancer with mammography. Cochrane Database Syst. Rev. 2013, 2013, https://doi.org/10.1002/14651858.CD001877.pub5.

8. Zubor, P.; Kubatka, P.; Kajo, K.; Dankova, Z.; Polacek, H.; Bielik, T.; Kudela, E.; Samec, M.; Liskova, A.; 
Vlcakova, D.; et al. Why the gold standard approach by mammography demands extension by multiomics? Application of liquid biopsy mirna profiles to breast cancer disease management. Int. J. Mol. Sci. 2019, 20, https://doi.org/10.3390/ijms20122878.

9. Brem, R.F.; Lenihan, M.J.; Lieberman, J.; Torrente, J. Screening breast ultrasound: Past, present, and future. Am. J. Roentgenol. 2015, 204, 234-240, https://doi.org/10.2214/AJR.13.12072.

10. Sutton, E.J.; Braunstein, L.Z.; El-Tamer, M.B.; Brogi, E.; Hughes, M.; Bryce, Y.; Gluskin, J.S.; Powell, S.; Woosley, A.; Tadros, A.; et al. Accuracy of Magnetic Resonance Imaging-Guided Biopsy to Verify Breast Cancer Pathologic Complete Response after Neoadjuvant Chemotherapy: A Nonrandomized Controlled Trial. JAMA Netw. Open 2021, 4, 1-10, https://doi.org/10.1001/jamanetworkopen.2020.34045.

11. Jatoi, I.; Pinsky, P.F. Breast Cancer Screening Trials: Endpoints and Overdiagnosis. JNCI J. Natl. Cancer Inst. 2020, 113, 1-5, https://doi.org/10.1093/jnci/djaa140.

12. Mishra, A.K.; Roy, P.; Bandyopadhyay, S.; Das, S.K. Breast ultrasound tumour classification: A Machine Learning-Radiomics based approach. Expert Syst. 2021, 1-12, https://doi.org/10.1111/exsy.12713.

13. Zhang, H.; Han, L.; Chen, K.; Peng, Y.; Lin, J. Diagnostic Efficiency of the Breast Ultrasound ComputerAided Prediction Model Based on Convolutional Neural Network in Breast Cancer. J. Digit. Imaging 2020, 33, 1218-1223, https://doi.org/10.1007/s10278-020-00357-7.

14. Busko, E.A.; Semiglazov, V.V.; Mishchenko, A.V.; Shishova, A.S.; Smirnova, V.O.; Kostromina, E.V.; Chernaya, A.V.; Artemieva, A.S.; Kryvorotko, P.V. Diagnostic value of ultrasound color Doppler mapping in early detection of breast cancer. Sib. J. Oncol. 2019, 18, 12-19, https://doi.org/10.21294/1814-4861-201918-6-12-19.

15. Schäfgen, B.; Juskic, M.; Radicke, M.; Hertel, M.; Barr, R.; Pfob, A.; Togawa, R.; Nees, J.; von Au, A.; Fastner, S.; et al. Evaluation of the FUSION-X-US-II prototype to combine automated breast ultrasound and tomosynthesis. Eur. Radiol. 2021, 31, 3712-3720, https://doi.org/10.1007/s00330-020-07573-3.

16. Jia, M.; Lin, X.; Zhou, X.; Yan, H.; Chen, Y.; Liu, P.; Bao, L.; Li, A.; Basu, P.; Qiao, Y.; et al. Diagnostic performance of automated breast ultrasound and handheld ultrasound in women with dense breasts. Breast Cancer Res. Treat. 2020, 181, 589-597, https://doi.org/10.1007/s10549-020-05625-2.

17. Choi, W.J.; Kim, S.H.; Shin, H.J.; Bang, M.; Kang, B.J.; Lee, S.H.; Chang, J.M.; Moon, W.K.; Bae, K.; Kim, H.H. Automated breast US as the primary screening test for breast cancer among East Asian women aged 40-49 years: a multicenter prospective study. Eur. Radiol. 2021, https://doi.org/10.1007/s00330-021-078643.

18. Wang, Y.; Choi, E.J.; Choi, Y.; Zhang, H.; Jin, G.Y.; Ko, S.B. Breast Cancer Classification in Automated Breast Ultrasound Using Multiview Convolutional Neural Network with Transfer Learning. Ultrasound Med. Biol. 2020, 46, 1119-1132, https://doi.org/10.1016/j.ultrasmedbio.2020.01.001.

19. Hennedige, T.; Venkatesh, S.K. Imaging of hepatocellular carcinoma: diagnosis, staging and treatment monitoring. Cancer Imaging 2012, 12, 530.

20. Oon, W.O.O.K.Y.M.; Hen, Y.I.E.I.S.; Hiun, C.; Uang, H.H.; Hiang, L.I.E.N.C. Original Contribution COMPUTER-AIDED DIAGNOSIS FOR THE CLASSIFICATION OF BREAST MASSES IN AUTOMATED WHOLE BREAST ULTRASOUND IMAGES 2011, 37, 539-548, https://doi.org/10.1016/j.ultrasmedbio.2011.01.006.

21. Zhang, Y.Z.; Xu, T.; Gong, H.Y.; Li, C.Y.; Ye, X.H.; Lin, H.J.; Shen, M.P.; Duan, Y.; Yang, T.; Wu, X.H. Application of high-resolution ultrasound, real-time elastography, and contrast-enhanced ultrasound in differentiating solid thyroid nodules. Med. (United States) 2016, 95, https://doi.org/10.1097/MD.0000000000005329.

22. Soto, A.M.; Sonnenschein, C. Information, programme, signal: dead metaphors that negate the agency of organisms. Interdiscip. Sci. Rev. 2020, 45, 331-343.

23. Tan-wong, S.M.; French, J.D.; Proudfoot, N.J.; Brown, M.A. Dynamic interactions between the promoter and terminator regions of the mammalian BRCA1 gene 2008.

24. Bane, A.L.; Beck, J.C.; Bleiweiss, I.; Buys, S.S.; Catalano, J.E.; Daly, M.B.; Giles, G.; Godwin, A.K.; Hibshoosh, H.; Hopper, J.L.; et al. BRCA2 Mutation-associated Breast Cancers Exhibit a Distinguishing Phenotype Based on Morphology and Molecular Profiles From Tissue Microarrays 2007, 31, 121-128.

25. Deng, C. BRCA1: cell cycle checkpoint, genetic instability, DNA damage response and cancer evolution 2006, 34, 1416-1426, https://doi.org/10.1093/nar/gkl010.

26. Demeunynck, M.; Bailly, C.; Wilson, W.D. Small molecule DNA and RNA binders: from synthesis to nucleic acid complexes; John Wiley \& Sons, 2006; 2; ISBN 3527605665.

27. Phan, A.T. Human telomeric G-quadruplex: structures of DNA and RNA sequences. FEBS J. 2010, 277, 1107-1117.

28. Cummings, C.A.; Peters, E.; Lacroix, L.; Andre, F.; Lackner, M.R. The Role of Next Generation Sequencing in Enabling Personalized Oncology Therapy History and overview of NGS technology. Clinical And Translational Science 2016, 9, 1-27, https://doi.org/10.1111/cts.12429.

29. Schwarzenbach, H.; Mueller, V.; Milde-Langosch, K.; Steinbach, B.; Pantel, K. Evaluation of cell-free tumour DNA and RNA in patients with breast cancer and benign breast disease. Mol. Biosyst. 2011, 7, 28482854.

30. Papadopoulou, E.; Davilas, E.; Sotiriou, V.; Georgakopoulos, E.; Koliopanos, A.; Aggelakis, F.; Dardoufas, 
K.; Agnanti, N.J.; Karydas, I.; Nasioulas, G. Cell-free DNA and RNA in Plasma as a New Molecular Marker for Prostate. Annals of the New York Academy of Sciences 2006, 243, 235-243, https://doi.org/10.1196/annals.1368.032.

31. Nattestad, M.; Goodwin, S.; Ng, K.; Baslan, T.; Sedlazeck, F.J.; Rescheneder, P.; Garvin, T.; Fang, H.; Gurtowski, J.; Hutton, E. Complex rearrangements and oncogene amplifications revealed by long-read DNA and RNA sequencing of a breast cancer cell line. Genome Res. 2018, 28, 1126-1135.

32. Huang, L.H.; Lin, P.H.; Tsai, K.W.; Wang, L.J.; Huang, Y.H.; Kuo, H.C.; Li, S.C. The effects of storage temperature and duration of blood samples on DNA and RNA qualities. PLoS One 2017, 12, e0184692.

33. Gallagher, S.R. Quantitation of DNA and RNA with absorption and fluorescence spectroscopy. Curr. Protoc. Neurosci. 2011, 1-14, https://doi.org/10.1002/0471142301.nsa01ks56.

34. Li, S.; Chen, L.; Li, J.; Liu, J. Comparison of different protocols of RNA preparation from circulating blood for RNA sequencing. Biotechnol. Lett. 2021, 8, https://doi.org/10.1007/s10529-021-03152-8.

35. Watanabe, K.; Akutsu, T. Evaluation of a co-extraction kit for mRNA, miRNA and DNA methylation-based body fluid identification. Leg. Med. 2020, 42, https://doi.org/10.1016/j.legalmed.2019.101630.

36. Frackowiak, D. The Jablonski diagram. J. Photochem. Photobiol. B Biol. 1988, 2, 399, https://doi.org/10.1016/1011-1344(88)85060-7.

37. Ager, D.J. The body's 'protective defences' (en- zymes, storage proteins and biological antioxidants) are next discussed, in chapters which describe the control of O 2. 2000, 285, 2000.

38. Diaspro, A. Introduction: Advanced multiphoton and fluorescence lifetime imaging techniques. Microsc. Res. Tech. 2007, 70, 397, https://doi.org/10.1002/jemt.20464.

39. Lu, G.; Little, J. V; Wang, X.; Zhang, H.; Patel, M.R.; Griffith, C.C.; El-Deiry, M.W.; Chen, A.Y.; Fei, B. Detection of head and neck cancer in surgical specimens using quantitative hyperspectral imaging. Clin. Cancer Res. 2017, 23, 5426-5436.

40. Aboughaleb, I.H.; Aref, M.H.; El-Sharkawy, Y.H. Hyperspectral imaging for diagnosis and detection of exvivo breast cancer. Photodiagnosis Photodyn. Ther. 2020, 31, 101922, https://doi.org/10.1016/j.pdpdt.2020.101922.

41. Aref, M.H.; Aboughaleb, I.H.; El-Sharkawy, Y.H. Custom optical imaging system for ex-vivo breast cancer detection based on spectral signature. Surg. Oncol. 2020, 35, 547-555, https://doi.org/10.1016/j.suronc.2020.10.019.

42. Aref, M.; Aboughaleb, I.H.; Youssef, A.-B.; El-Sharkawy, Y. Novel Approach Exploiting the Hyperspectral Imaging System for Breast Cancer Therapy and Diagnosis. Arch. Breast Cancer 2020, 7, 189-201, https://doi.org/10.32768/abc.202074189-201.

43. Schuster, D.M.; Nieh, P.T.; Chen, G.Z. Hyperspectral imaging and quantitative analysis for prostate cancer detection. J. of Biomedical Optics 2020, https://doi.org/10.1117/1.JBO.17.7.076005.

44. Landro, M. De; Saccomandi, P.; Barberio, M.; Schena, E.; Member, S.; Diana, M. Hyperspectral imaging for thermal effect monitoring in in vivo liver during laser ablation 201941 st Annu. Int. Conf. IEEE Eng. Med. Biol. Soc. 2019, 1851-1854, https://doi.org/10.1109/EMBC.2019.8856487.

45. Aref, M.H.; Aboughaleb, I.H.; El-sharkawy, Y.H. Photodiagnosis and Photodynamic Therapy Tissue characterization utilizing hyperspectral imaging for liver thermal ablation. Photodiagnosis Photodyn. Ther. 2020, 31, 101899, https://doi.org/10.1016/j.pdpdt.2020.101899.

46. Aref, M.H. Biomedical Research and Clinical Reviews. Biomed. Res. Clin. Rev. 2020, 1, 1-13, https://doi.org/10.31579/brcr.2020/005.

47. Aref, M.H.; Aboughaleb, I.H.; Youssef, A.-B.M.; El-Sharkawy, Y.H. Hyperspectral image-based analysis of thermal damage for ex-vivo bovine liver utilizing radiofrequency ablation. Surg. Oncol. 2021, 101564, https://doi.org/10.1016/j.suronc.2021.101564.

48. Landro, M. D.; Esp, I.; Barberio, M.; Felli, E.; Agnus, V.; Pizzicannella, M.; Diana, M.; Zappa, E.; Saccomandi, P. Hyperspectral Imagery for Assessing Laser-Induced Thermal State Change in Liver. Sensors 2021, https://doi.org/10.3390/s21020643.

49. Fouad Aref, M.H.; Sharawi, A.A.R.; El-Sharkawy, Y.H. Delineation of the Arm Blood Vessels Utilizing Hyperspectral Imaging to Assist with Phlebotomy for Exploiting the Cutaneous Tissue Oxygen Concentration. Photodiagnosis Photodyn. Ther. 2021, 33, https://doi.org/10.1016/j.pdpdt.2021.102190.

50. Rubins, U.; Grabovskis, A.; Cimurs, J.; Marcinkevics, Z.; Caica, A. Hyperspectral evaluation of skin blood oxygen saturation at baseline and during arterial occlusion. SPIE Photonics Europe 2018, 42, https://doi.org/10.1117/12.2306131.

51. Geneaid Total RNA Extraction and Purification Available online: www.geneaid.com.

52. Noor, S.S.M.; Michael, K.; Marshall, S.; Ren, J. Hyperspectral image enhancement and mixture deep-learning classification of corneal epithelium injuries. Sensors (Switzerland) 2017, 17, https://doi.org/10.3390/s17112644.

53. Kumar, V.; Gupta, P. Importance of Statistical Measures in Digital Image Processing. Int. J. Emerg. Technol. Adv. Eng. 2012, 2, 56-62.

54. Ferlay, J.; Soerjomataram, I.; Dikshit, R.; Eser, S.; Mathers, C.; Rebelo, M.; Parkin, D.M.; Forman, D.; Bray, F. Cancer incidence and mortality worldwide: sources, methods and major patterns in GLOBOCAN 2012. 
Int. J. cancer 2015, 136, E359-E386.

55. Tazhibi, M.; Dehkordi, Z.F.; Babazadeh, S. Trends in breast cancer incidence rates by age and tumor characteristics of women in the city of Isfahan for the period 2001-2010: An application of joinpoint analysis. J. Res. Med. Sci. 2014, 19, 319-325.

56. Jemal, A.; Ward, E.; Thun, M.J. Recent trends in breast cancer incidence rates by age and tumor characteristics among U.S. women. Breast Cancer Res. 2007, 9, 1-6, https://doi.org/10.1186/bcr1672.

57. Fendt, L.; Niederstätter, H.; Huber, G.; Zelger, B.; Dünser, M.; Seifarth, C.; Röck, A.; Schäfer, G.; Klocker, H.; Parson, W. Accumulation of mutations over the entire mitochondrial genome of breast cancer cells obtained by tissue microdissection. Breast Cancer Res. Treat. 2011, 128, 327-336, https://doi.org/10.1007/s10549-010-1092-8.

58. Narod, S.A.; Iqbal, J.; Miller, A.B. Why have breast cancer mortality rates declined? J. Cancer Policy 2015, 5, 8-17, https://doi.org/10.1016/j.jcpo.2015.03.002.

59. Lannin, D.R.; Wang, S. Are Small Breast Cancers Good because They Are Small or Small because They Are Good? N. Engl. J. Med. 2017, 376, 2286-91, https://doi.org/10.1056/nejmsr1613680.

60. Talhouet, S. De; Peron, J.; Vuilleumier, A.; Friedlaender, A.; Viassolo, V.; Ayme, A.; Bodmer, A.; Treilleux, I.; Lang, N.; Tille, J.C.; Chappuis, P. O.; Buisson, A.; Giraud, S.; Lasset, C.; Bonadona, V.; Tredan, O.; Labidi-Galy, S.I. Clinical outcome of breast cancer in carriers of BRCA1 and BRCA2 mutations according to molecular subtypes. Sci. Rep. 2020, 10, 1-9, https://doi.org/10.1038/s41598-020-63759-1.

61. Pandit, P.; Patil, R.; Palwe, V.; Gandhe, S.; Patil, R.; Nagarkar, R. Prevalence of Molecular Subtypes of Breast Cancer: A Single Institutional Experience of 2062 Patients. Eur. J. Breast Heal. 2020, 16, 39-43, https://doi.org/10.5152/ejbh.2019.4997.

62. Zhang, X.; Ju, S.; Wang, X.; Cong, H. Advances in liquid biopsy using circulating tumor cells and circulating cell-free tumor DNA for detection and monitoring of breast cancer. Clin. Exp. Med. 2019, 19, 271-279, https://doi.org/10.1007/s10238-019-00563-w.

63. Singh, N.; Bhatia, P.; Bhatti, R.; Jaggi, A.S. Apoptosis as a warrior or an opponent. In Clinical Perspectives and Targeted Therapies in Apoptosis; Elsevier, 2021; 111-125.

64. Koren, E.; Fuchs, Y. Modes of Regulated Cell Death in Cancer. Cancer Discov. 2021, 11, 245 - 265 , https://doi.org/10.1158/2159-8290.CD-20-0789.

65. Pestrin, M.; Salvianti, F.; Galardi, F.; De Luca, F.; Turner, N.; Malorni, L.; Pazzagli, M.; Di Leo, A.; Pinzani, P. Heterogeneity of PIK3CA mutational status at the single cell level in circulating tumor cells from metastatic breast cancer patients. Mol. Oncol. 2015, 9, 749-757, https://doi.org/10.1016/j.molonc.2014.12.001. 


\section{Appendix}
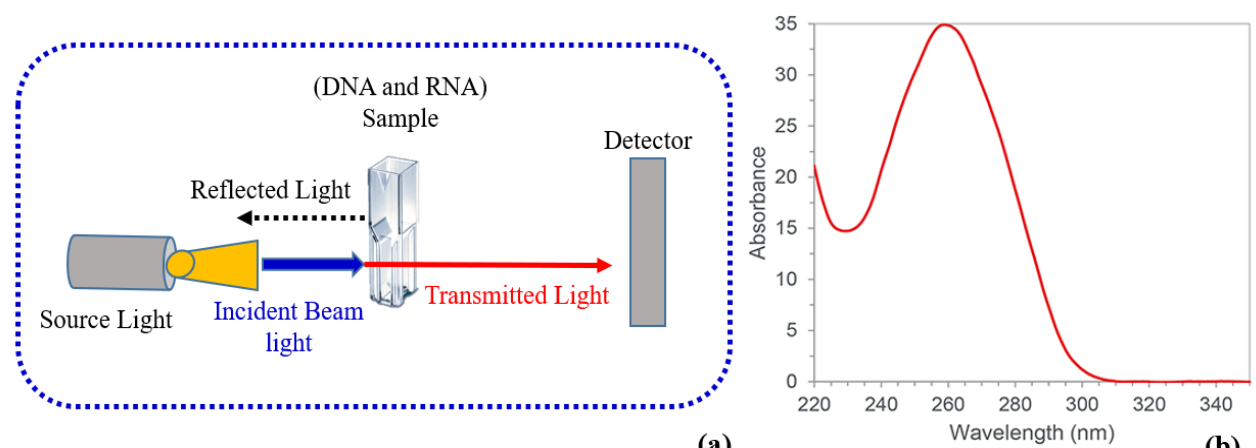

(a)

Figure A1. (a) The schematic Diagram of the Photometry (UV-Vis) demonstrating the optical signal measurement idea for the calculation of the absorption value of the investigated sample, (b) The ideal signal for the intrinsic absorptivity properties of nucleic acids (DNA and RNA) with peak at $260 \mathrm{~nm}$.
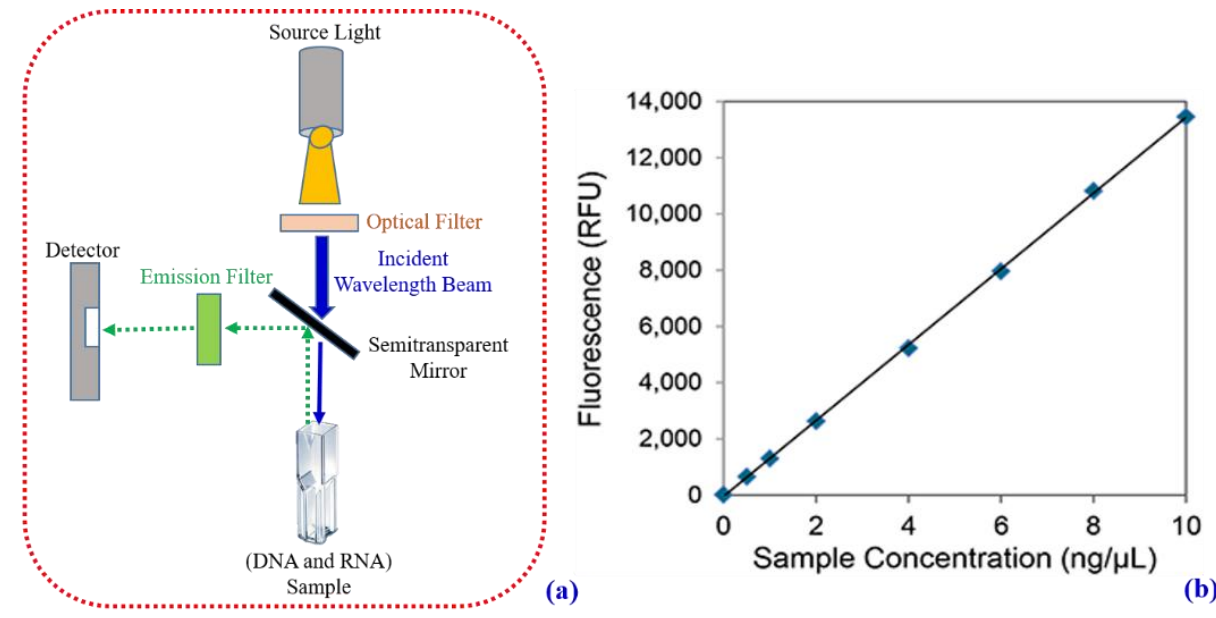

Figure A2. (a) The schematic Diagram of the fluorescence RNA/DNA quantification demonstrating the optical measurement theory for the investigated sample excitation with selective wavelength from the source light, (b)

The measured nucleic acids Concentrations are calculated from the Fluorescence signal of the investigated sample and the Standard Curve of known concentration.

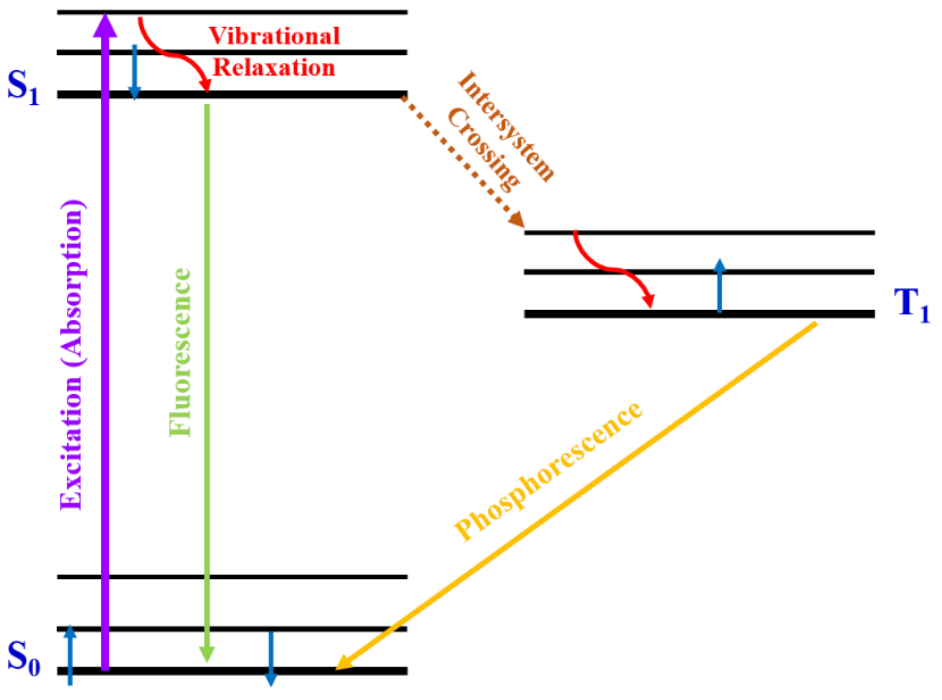

Figure A3. The Jablonski diagram introduces that the light absorption provides sufficient energy to provide the necessary excitation for the electron to move from energy level $\left(S_{0}\right)$ to level $\left(S_{1}\right)$, then due to the vibrational relaxation release equal amount of energy as "Fluorescence" and the intersystem crossing process as

"Phosphorescence", and the spontaneous low-intensity transition as "Delayed Fluorescence", the amount of exciting energy and the reasonable time various regarding the type of the material and exploited light. 

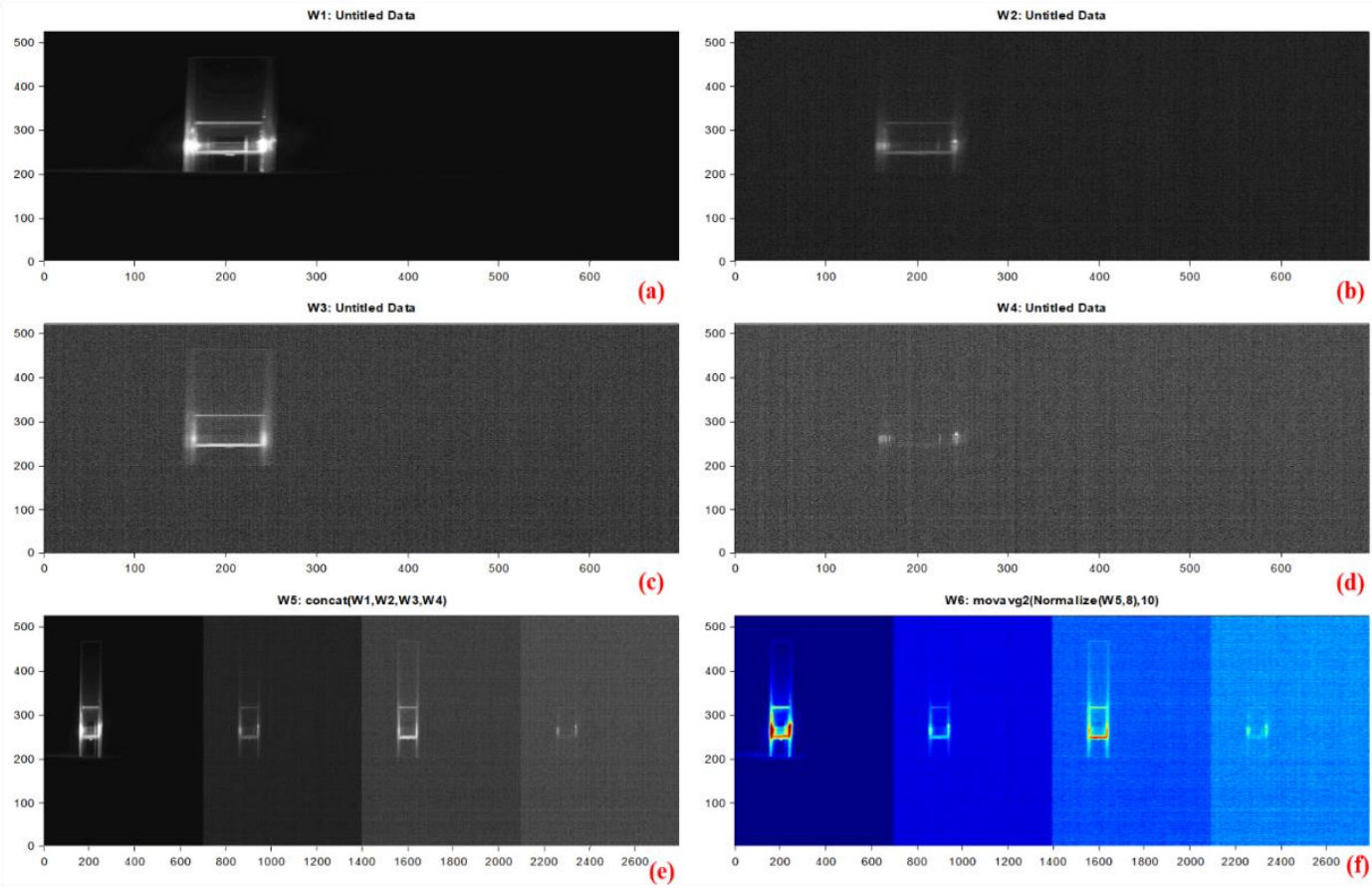

Figure A4. The worksheet of the spectral images for the investigated normal control total RNA samples; (a) The scanned spectral image of the sample at a wavelength $(395 \mathrm{~nm})$ regarding the excitation source light (UV, $20 \mathrm{~mW}, 395 \mathrm{~nm})$, (b) The scanned spectral image of the sample at a wavelength $(431 \mathrm{~nm})$ does not represent any emissions or glowing, (c) The scanned spectral image of the sample at a wavelength (493 nm) shows high emission, (d) The scanned spectral image of the sample at a wavelength $(768 \mathrm{~nm})$ is almost disappeared with no emission, (e) The collage Image of the scanned samples spectral images at the various wavelengths (395, 431, 493, and $768 \mathrm{~nm}$ ), (f) The collage Image of the scanned samples spectral images after applying the custom image processing (normalization, Moving average filter) to remove the background noise.
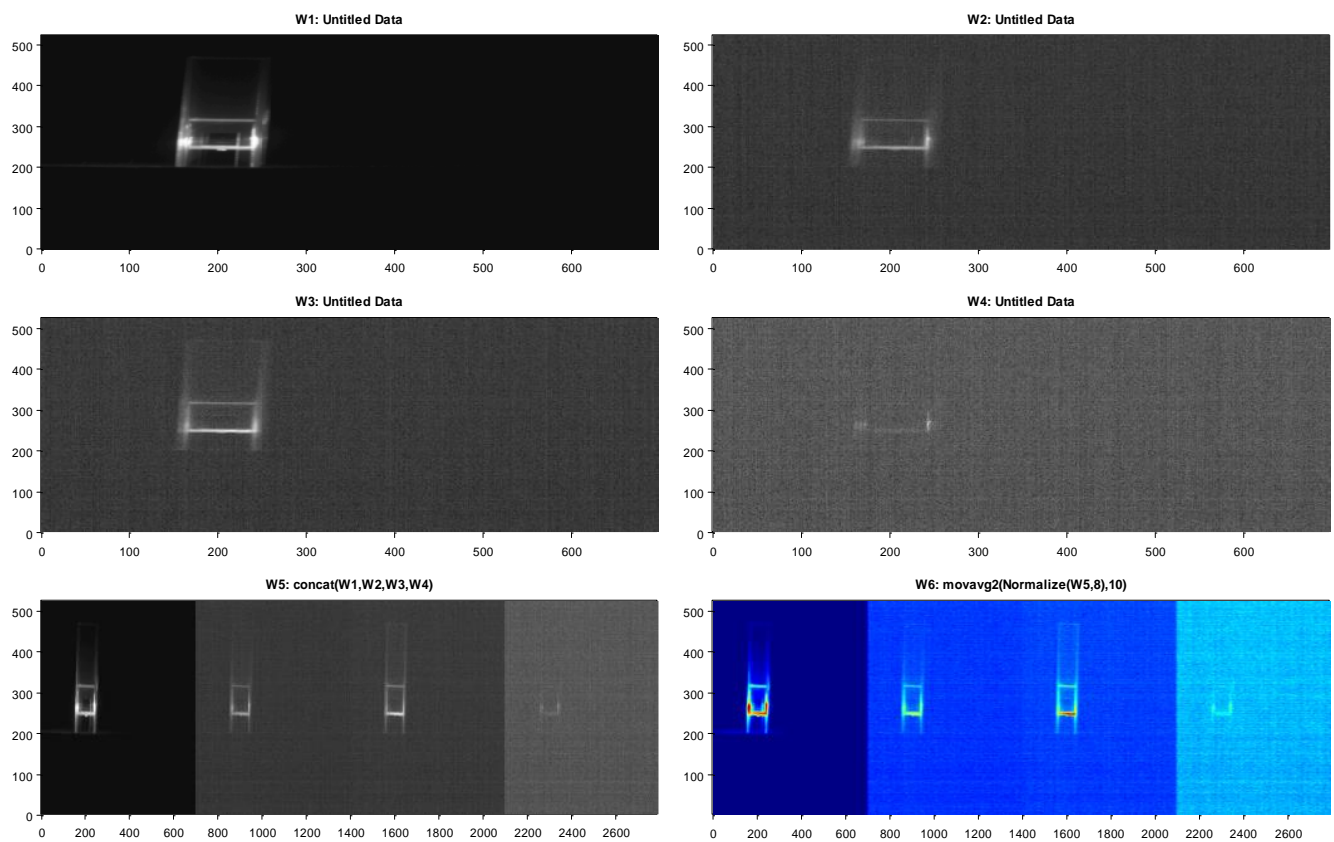

Figure A5. The worksheet of the spectral images for the investigated HCC total RNA samples; (a) The scanned spectral image of the sample at wavelength $(395 \mathrm{~nm})$ regarding the excitation source light (UV, $20 \mathrm{~mW}, 395$ $\mathrm{nm})$, (b) The scanned spectral image of the sample at wavelength $(431 \mathrm{~nm})$ represents a little bit emission, (c) The scanned spectral image of the sample at wavelength $(493 \mathrm{~nm})$ provides high emission, (d) The scanned spectral image of the sample at wavelength $(768 \mathrm{~nm})$ is almost vanished with no emission, (e) The collage Image of the scanned samples spectral images at the various wavelengths (395, 431, 493, and $768 \mathrm{~nm})$, (f) The collage Image of the scanned samples spectral images after applying the custom image processing (normalization, Moving average filter) to remove the background noise. 

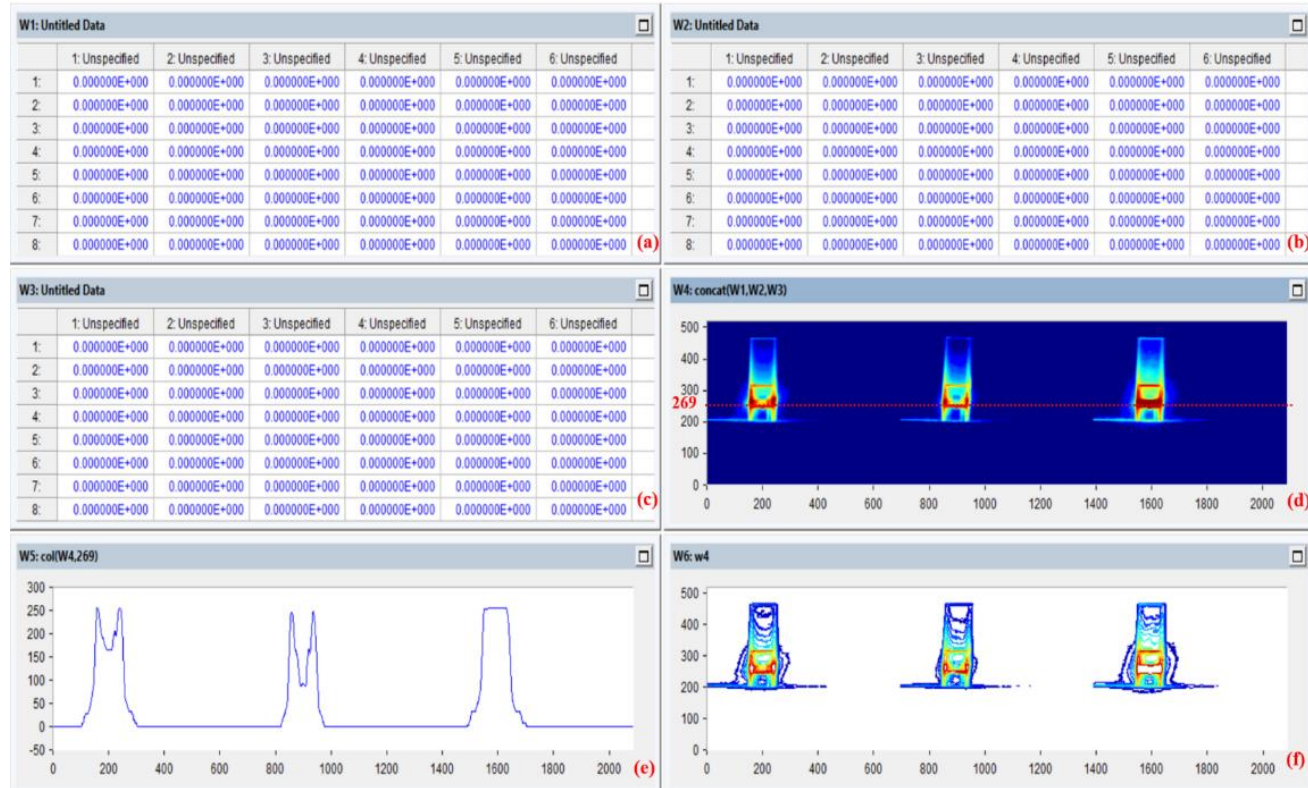

Figure A6. The entire worksheet of the three investigated samples (Normal subject / HCC Patient / Breast Cancer Patient) at wavelength $395 \mathrm{~nm}$; (a) The matrix of the spectral images for the investigated normal total RNA samples at wavelength $395 \mathrm{~nm}$, (b) The matrix of the spectral images for the investigated HCC total RNA samples at wavelength $395 \mathrm{~nm}$, (c) The matrix of the spectral images for the investigated breast cancer total RNA samples at wavelength $395 \mathrm{~nm}$, (d) The collage Image of the scanned samples spectral images after applying the custom image processing (normalization, Moving average filter) to remove the background noise with a scanned line at (269 Y-axis) to monitor the emission intensity for each case, (e) The emission Intensity for the various investigated samples (Normal subject / HCC Patient / Breast Cancer Patient) to highlight the difference for each case, (f) The contour mapping for the emission for the various investigated samples (Normal subject / HCC Patient / Breast Cancer Patient).

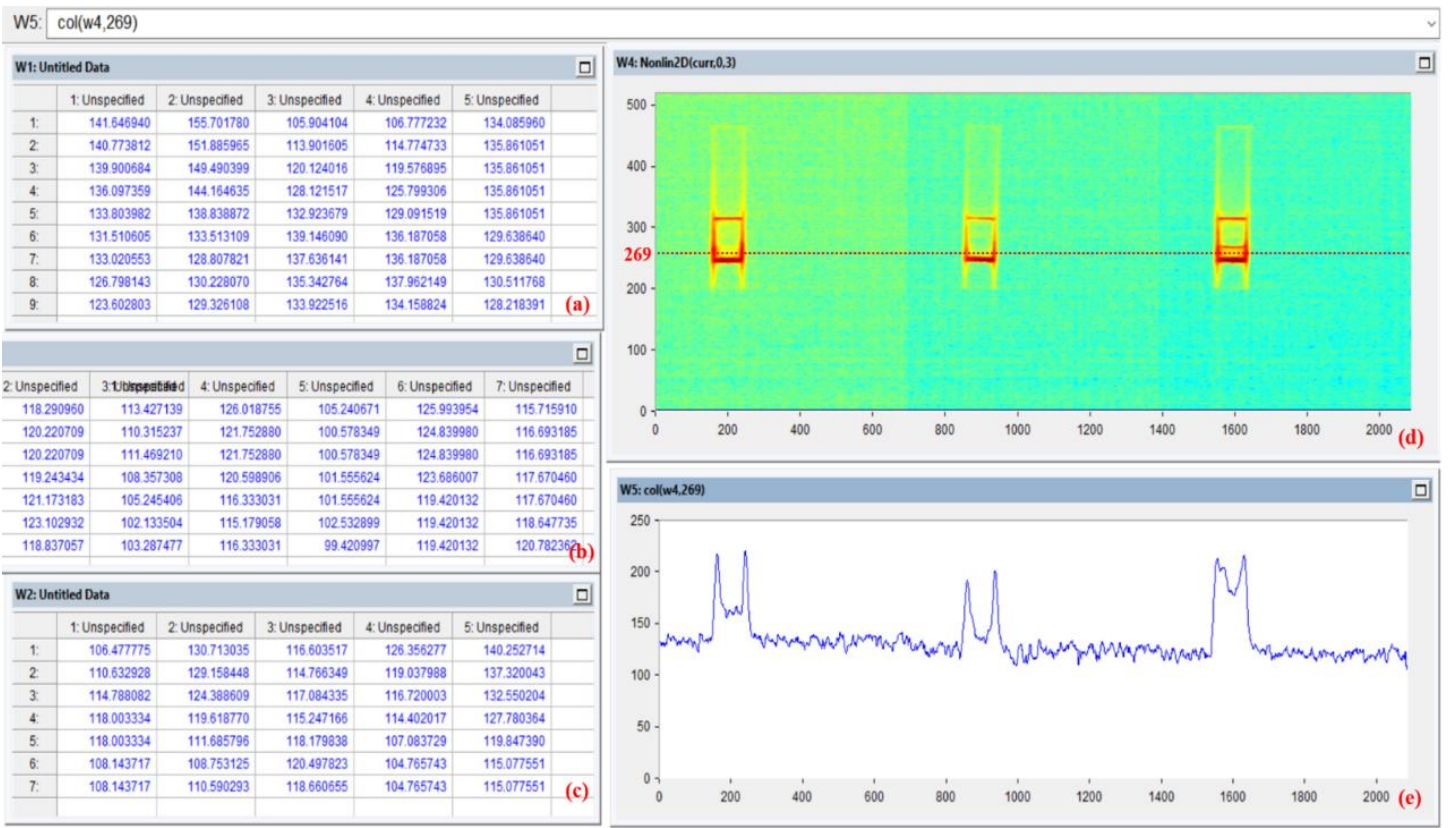

Figure A7. The entire worksheet of the three investigated samples (Normal subject / HCC Patient / Breast Cancer Patient) at wavelength $431 \mathrm{~nm}$; (a) The matrix of the spectral images for the investigated normal total RNA samples at wavelength $431 \mathrm{~nm}$, (b) The matrix of the spectral images for the investigated HCC total RNA samples at wavelength $431 \mathrm{~nm}$, (c) The matrix of the spectral images for the investigated breast cancer total RNA samples at wavelength $431 \mathrm{~nm}$, (d) The collage Image of the scanned samples spectral images after applying the custom image processing (normalization, Moving average filter) to remove the background noise with a scanned line at (269 Y-axis) to monitor the emission intensity for each case, (e) The emission Intensity for the various investigated samples (Normal subject / HCC Patient / Breast Cancer Patient) to highlight the difference for each case. 


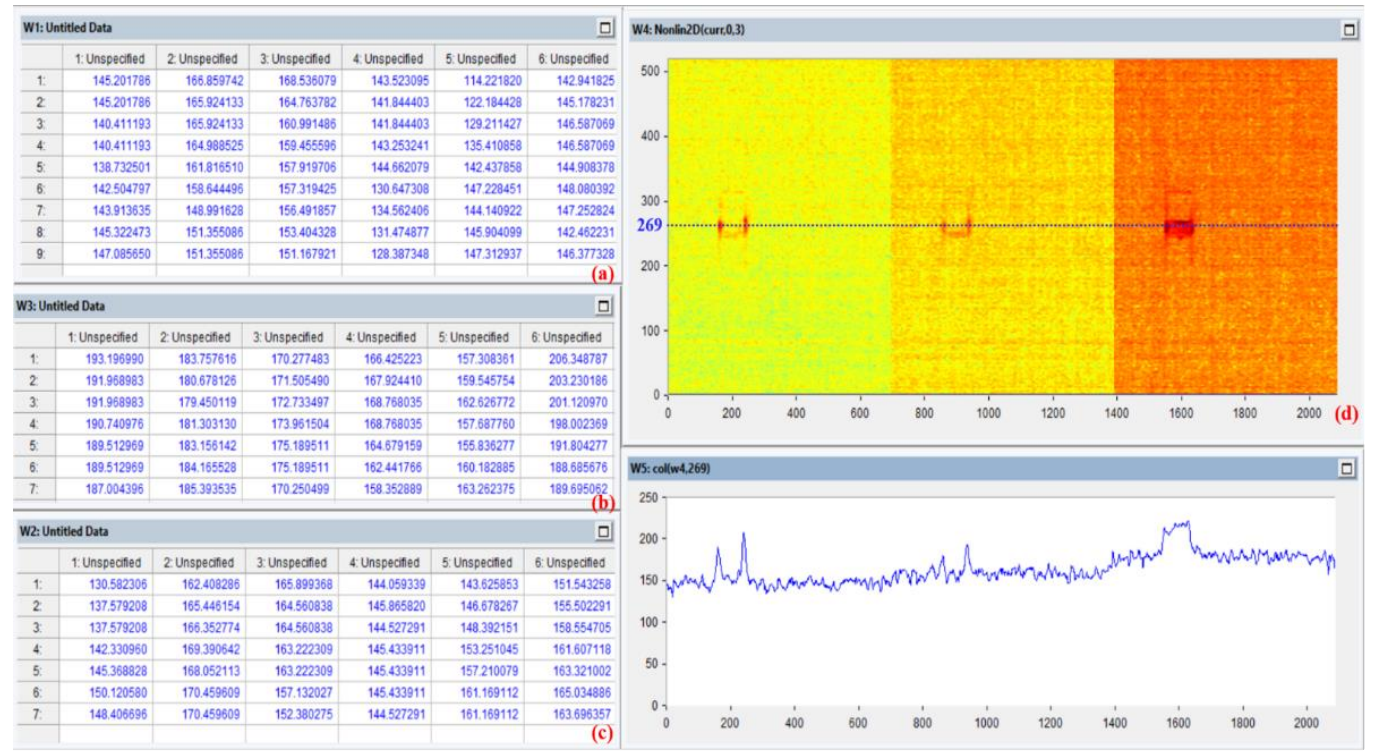

Figure A8. The entire worksheet of the three investigated samples (Normal subject / HCC Patient / Breast Cancer Patient) at wavelength $768 \mathrm{~nm}$; (a) The matrix of the spectral images for the investigated normal total RNA samples at wavelength $768 \mathrm{~nm}$, (b) The matrix of the spectral images for the investigated HCC total RNA samples at wavelength $768 \mathrm{~nm}$, (c) The matrix of the spectral images for the investigated breast cancer total RNA samples at wavelength $768 \mathrm{~nm}$, (d) The collage Image of the scanned samples spectral images after applying the custom image processing (normalization, Moving average filter) to remove the background noise with a scanned line at (269 Y-axis) to monitor the emission intensity for each case, (e) The emission Intensity for the various investigated samples (Normal subject / HCC Patient / Breast Cancer Patient) to highlight the difference for each case. 